\title{
Mistakes in Mathematical Formalism of the Stephen Hawking's Doctoral Thesis
}

\section{Horacio Useche Losada*}

Department of Applied Mathematics, Surcolombiana University in Neiva, Huila, Colombia

\begin{abstract}
We present to the international scientific community a series of misprint and some mathematical mistake found in Stephen Hawking's doctoral thesis, titled IProperties of Expanding Universe". These errors have been found as a result of my translation work into Spanish of the aforementioned thesis.
\end{abstract}

\section{Introduction}

We present to the international scientific community a series of misprint and some mathematical mistake found in Stephen Hawking's doctoral thesis. These errors have been found as a result of my translation work into Spanish of the aforementioned thesis. As it is of public knowledge, the thesis of Hawking has been released to the public by the University of Cambridge and we have used it to translate it into Spanish and simultaneously edit all its equations in LATEX format, which were written by hand by its author during of Cambridge whose names do not appear in the thesis. As director of the thesis was the astrophysicist Dr. D. W. Sciama ${ }^{1}$.

As a result of this work and to my surprise, we have been able to find:

- Several typographical errors that, however, can be seen as spelling mistakes

- Some errors associated with the mathematical formalism used by Hawking in his doctoral thesis.

In the following sections we describe such inconveniences [1-8].

\section{Spelling Mistakes}

Hawking's thesis was typed and we understand that this work was carried out by his first wife. Table 1 summarizes the errata that were identified in this sense and that correspond basically to spelling mistakes.

\section{Mistake in Mathematical Formalism}

Pg 17

In the Hoyle-Narlikar field equations, Hawking's original presents an error in this equation, namely the term $2\left(\mathrm{~m}^{(\mathrm{a})}{ }_{\mathrm{i}} \mathrm{m}^{(\mathrm{b})}{ }_{\mathrm{ik}}\right)$ appears without closing its second parenthesis. In fact, LATEX would not allow to write it that way (Figure 1).

$\operatorname{Pg} 28$

Hawking writes ( $\mathrm{qa} ; \mathrm{qb}=1$ instead of: ( $\mathrm{qa} ; \mathrm{qb}=1)$ (Figure 2$)$.

Table 1: Spelling mistakes in the Hawking's thesis.

\begin{tabular}{|l|l|l|}
\hline Page No & Spelling mistakes & Correction \\
\hline 15 & Claculated & Calculated \\
\hline 17 & Thereis & There is \\
\hline 25 & Claculating & Calculating \\
\hline 26 & Conformall flatness & Conformal flatness \\
\hline 29 & Hwever & However \\
\hline 50 & Diation & Dilation \\
\hline 50 & Radition & Radiation \\
\hline
\end{tabular}

${ }^{1}$ Dennis William Siahou Sciama was a British physicist, in particular one of the leading international experts in astrophysics and cosmology.

\section{Pg 31}

Hawking writes $\mathrm{Rab}=\mathrm{R}$ p o bp instead of: $\mathrm{Rab}=\mathrm{R} \mathrm{p}$ a bp is doing an operation of contraction of indices and instead of a a place what looks like a o or a zero (Figure 3 ).

Pg 32

Hawking writes $\sigma_{a b}=U_{(c ; d)} h_{\alpha}^{c}-\frac{1}{3} h_{a b} \Theta$ instead of: $\sigma_{a b}=U_{(c ; d)} h_{\alpha}^{c} h_{b}^{d}-\frac{1}{3} h_{a b} \Theta$. Clearly introduce a $a$ where a $a$ should go (Figure 4).

$\operatorname{Pg} 46$

Hawking writes ha(,/q $)^{\mathrm{rbs}} \mathrm{u}_{\mathrm{r}} \nabla_{\mathrm{s}}$ and it is not concretely understood what kind of covariant or contravariant tensor operation it wants to express (Figure 5).

\section{$\operatorname{Pg} 65$}

In equation 3.54 of the original an addition symbol is repeated twice: $3 v \psi_{0}+6(\gamma-\mu) \psi_{1} \ldots$ (Figure 6).

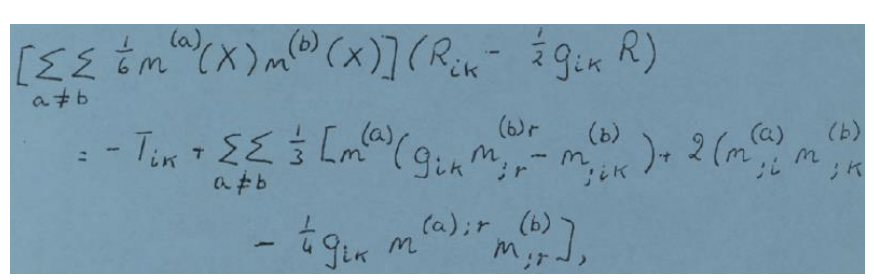

Figure 1: Page 17, he did not close a parenthesis.

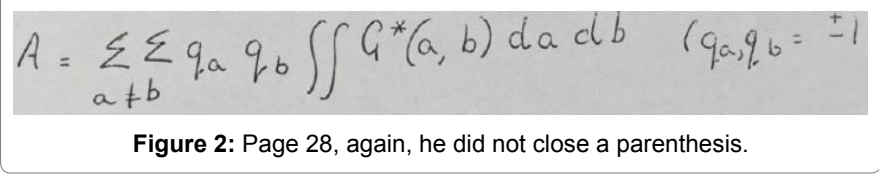

*Corresponding author: Horacio Useche Losada, Professor, Department of Applied Mathematics, Surcolombiana University in Neiva, Huila, Colombia, Tel: +573003825384; E-mail: horaciouseche@gmail.com

Received October 24, 2018; Accepted November 06, 2018; Published November 14,2018

Citation: Losada HU (2018) Mistakes in Mathematical Formalism of the Stephen Hawking's Doctoral Thesis. J Phys Math 9: 292. doi: 10.4172/2090-0902.1000292

Copyright: (c) 2018 Losada HU. This is an open-access article distributed under the terms of the Creative Commons Attribution License, which permits unrestricted use, distribution, and reproduction in any medium, provided the original author and source are credited. 
Citation: Losada HU (2018) Mistakes in Mathematical Formalism of the Stephen Hawking's Doctoral Thesis. J Phys Math 9: 292. doi: 10.4172/20900902.1000292

$\operatorname{Pg} 70$

On page 70 , equation 4.10 , Hawking seems to assign an exponent to the last of the components in this group of equations but it is illegible and it is also a component that is annulled (Figure 7).

\section{Pg 70}

On page 70, Hawking writes the set of components as $\psi^{\text {(something)s }}$ where the word "something" denotes an illegible symbol that could be

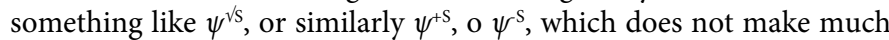
sense if the components are null (Figure 8).

\section{Pg 76}

Hawking writes: $\frac{\partial h}{\partial \Omega}\left(\Omega+\mathrm{O}(1)=\mathrm{O}\left(\Omega^{-1}\right)\right.$

instead of $\frac{\partial h}{\partial \Omega}(\Omega+\mathrm{O}(1))=\mathrm{O}\left(\Omega^{-1}\right)$.

forgetting to close a parenthesis, note the (Figure 9).

Pg 76

Hawking writes in the equation 6.15: .... $\left(-\frac{5}{4} A^{4}+4 A^{2} \rho^{0}-\rho \frac{0^{2}}{2}-G^{0} \bar{G}^{0}\right)$ instead of .... $\left(-\frac{5}{4} A^{4}+4 A^{2} \rho^{0}-\frac{1}{2} \rho^{0^{2}}-G^{0} \bar{G}^{0}\right)$ (Figure 10).

Pg 91

In the equation (7.35) Hawking writes: $\psi_{u}^{0}=\left[-\bar{G}^{0}+\frac{3}{2} G_{01}^{0}-\frac{1}{2} G_{0 ; 1}^{0}\right] \Omega^{-2} \ldots$ Instead of $\psi_{u}^{0}=\left[-\bar{G}^{0}+\frac{3}{2} G_{01}^{0}-\frac{1}{2} G_{0 ; 1}^{0}\right] \Omega^{-2} \ldots$ (Figure 11).

Pg 96

Hawking says: IWhen the six parameters a, b, c, d are given... "but it is evident that there are only four parameters to which it refers (Figure 12).

\section{Pg 120}

Hawking seems to have forgotten here the symbol to insert, which we believe is $\sigma$ but in its original, page 120, a blank space simply appears (Figure 13).

Because it is one of the most important contribution of Hawking to science, we hope that the University of Cambridge will correct these problems and publish a refined edition of this important scientific work [9-18].

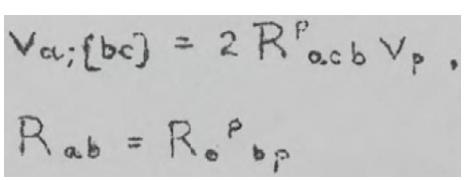

Figure 3: Page 31, wrong index.

$$
\sigma_{a b}=u_{(c ; d)} h_{\alpha}^{c} h_{b}^{d}-\frac{1}{3} h_{a b} \theta
$$

Figure 4: Page 32, wrong index.

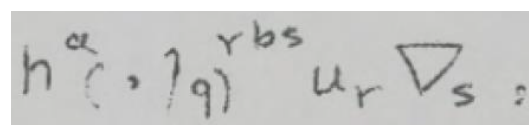

Figure 5: Page 46, undefined operation.

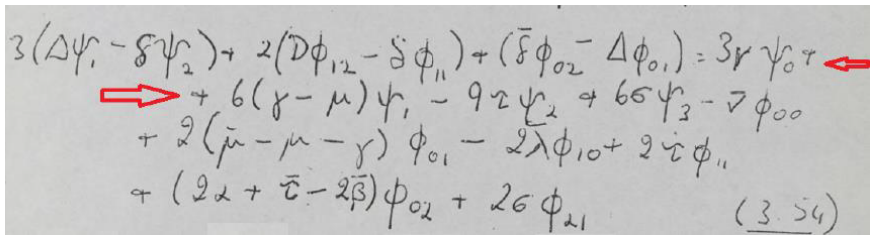

Figure 6: Page 65, redundancy of arithmetic operators.

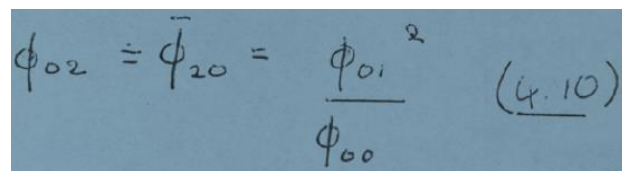

Figure 7: Page 70, excess unreadable and superfluous.

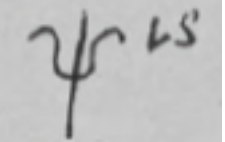

Figure 8: Page 70, illegible exponent.

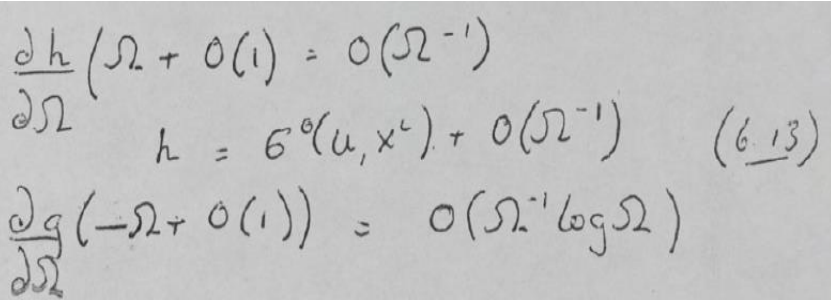

Figure 9: Page 76, another parenthesis that does not close.

$$
\begin{aligned}
& \rho=-2 \Omega^{-2}-A \Omega^{-3}+\rho^{0} \Omega^{-4}+\left(\frac{1}{2} A^{2}-2 A \rho^{0}\right) \Omega^{-5} \\
& +\left(-\frac{5}{4} A^{4}+4 A^{2} \rho^{0}-\rho^{0^{2}}-\frac{6^{0} \sigma^{-0}}{2}\right) \Omega^{-6}+0\left(\Omega^{-7}\right)(6.15)
\end{aligned}
$$

Figure 10: Page 76, invalid expression.

$$
\begin{aligned}
& \psi_{u}^{0}=\left[-\bar{\sigma}^{0}+\frac{3}{2} \sigma_{j i}^{0}+-\frac{1}{2} \sigma_{j i 1}^{0}\right] \Omega_{r}^{-2}\left[-\frac{\sigma^{0}}{2}-\frac{3}{4} \vec{\sigma}_{\mu}\right. \\
& \left.+\frac{1}{2} \bar{\sigma}_{, 11}^{0}\right] \Omega^{-3}+\left[A^{2}\left(\bar{\sigma}^{0}+\frac{3}{4} \bar{\sigma}_{, 1}^{0}-\frac{3}{8} \bar{\sigma}_{x_{1}}^{0}\right)\right. \\
& +\frac{A^{2}}{4}\left(-\bar{\sigma}^{0}+\frac{3}{2} \bar{\sigma}_{\mu}^{0}-\frac{1}{2} \bar{\sigma}_{\mu}^{0}\right) e^{2 u}-e^{2 u} \bar{\nabla} / s \\
& \left.x\left(\bar{\sigma}_{11}^{0}-\bar{\sigma}^{0}\right)^{\frac{3}{2}} \nabla\left(S\left(\bar{\sigma}_{11}^{0}-\bar{\sigma}^{0}\right)^{\frac{1}{2}}\right)\right) \\
& \left.+\frac{3 A}{8} \bar{\psi}_{0}^{0}\right] \Omega^{-4}+O\left(\Omega^{-5}\right)
\end{aligned}
$$

Figure 11: Page 91, two arithmetic operators followed superfluously. 
reduced the leading term of $g^{\ddot{f}}$ to a conformully flat form. Thus the only allowed transformations of $x^{i}$ are the conformal transformations of the form:

$$
x^{3}+i x^{4}=\frac{a\left(x^{3}+c x^{4}\right)+b}{a\left(x^{3}+i x^{4}\right)+b}
$$$$
a d-b c=1
$$

When the six parameters $a, b, c, d$ are given $K^{\prime}$ is uniquely aetermined by $(8.14) \mathrm{K}^{2}$ is also uniquely determined. Thus

Figure 12: Page 96, wrong reference to number of parameters.

which is critical will be said to be maximal if it corresponds to a local maximum of

Figure 13: Page 120, forgot to quote a numeric variable value.

\section{References}

1. Battaglia F, George T (2015) Tensor Calculus for Physics. American Journal of Physics 83: 478.

2. Bertschinger CE (1999) Introduction to Tensor Calculus for Genera Relativity. Massachusetts Institute of Technology, Department of Physics. Physics.

3. Chow TL (2000) Mathematical Methods for Physicists: A concise introduction. Cambridge University Press, p: 569.

4. Clarke D (2011) Tensor Calculus. Saint Marys University, p: 53.
5. Hawking WS (1966) Properties of Expanding Universe. Trinity Hall. Cambridge University, p: 134.

6. Hawking WS (1976) Black holes and thermodynamics. Phys Rev 13 7.

7. Hawking WS (1985) Arrow of time in cosmology. Phys Rev 32: 7.

8. Hawking WS, Gibbons GW (1976) Cosmological event horizons, thermodynamics, and particle creation. Phys Rev 15: 14.

9. Hawking WS, Moss IG, Stewart JM (1982) Bubble collisions in the very early universe. Phys Rev. 26: 13.

10. Hawking WS, Halliwell JJ (1984) Origin of structure in the Universe. Third Series 31: 1777

11. Janssen B (2013) Theory of General Relativity. University of Granada, p: 243.

12. Kolecki JC (2002) An Introduction to Tensors for Students of Physics and Engineering. Glenn Research Center, p: 29.

13.Tulio LC (1947) The Absolute Differential Calculus (Calculus of tensors). Blackie \& Son Limited, p: 476.

14.Misner CW, Thorne KS, Wheeler JA (1973) Gravitation. WH Freeman and Company, p: 1304.

15.Schiller C (2016) Motion Mountain. The Adventure of Physic Relativity and Cosmology 2: 370.

16.Spain B (1960) Tensor Calculus (3rdedn) Oliver and Boyd, p: 125.

17.Wald R (1984) General Relativity. The University of Chicago Chicago and London Press, p: 491.

18.Weinberg S (1972) Gravitation and Cosmology: Principles and Applications of the General Theory of Relativity. John Wiley and Sons, p: 641. 